\title{
DSC coupled with PCA as a tool for butter authenticity assessment
}

\author{
Jolanta Tomaszewska-Gras ${ }^{1}$
}

Received: 9 October 2015/ Accepted: 6 February 2016/Published online: 26 February 2016

(C) The Author(s) 2016. This article is published with open access at Springerlink.com

\begin{abstract}
The authenticity assessment of butter is still a big challenge for analytics. Due to its low cost, palm oil (PO) is the edible fat most frequently used as an adulterant in the production of butter. The aim of this study was to test the feasibility of the DSC technique coupled with principal component analysis (PCA) for the distinction of pure butterfat from adulterated. A differential scanning calorimeter DSC 7 from Perkin-Elmer was used for the examination of crystallization and melting properties of pure butterfat and its mixtures with PO $(2,5,10,15,20,25,30,35 \%$ w/w $)$. The addition of $\mathrm{PO}$ affects the thermodynamic parameters of the crystallization and melting of butter, which modifies the position and area of phase transition peaks. A large dataset concerning DSC cooling and heating parameters such as temperatures, enthalpies and peak heights was obtained. Processing of data was supported by the PCA method, which proved its applicability for differentiation between genuine and adulterated fat. Statistical analysis revealed that the best separation of samples with different palm oil concentration was achieved using DSC melting parameters of enthalpies and peak heights of low and medium melting fractions. PCA of crystallization parameters did not give such distinct separation. The results of this study confirmed that the DSC technique coupled with PCA can be successfully applied to detect with high sensitivity (from $2 \%$ ) the adulterant in butter.
\end{abstract}

Jolanta Tomaszewska-Gras

gras@up.poznan.pl

1 Department of Food Quality Management, Poznań University of Life Sciences, ul. Wojska Polskiego 31/33, 60-637 Poznan, Poland
Keywords Milk fat $\cdot$ Authenticity $\cdot$ Palm oil · Melting · Crystallization · DSC · Principal component analysis (PCA)

\section{Introduction}

Authenticity is one of the attributes of food quality. Many food products were and are adulterated, and butter in this case is no exception. Butter can be made only from milk, and its term is legally protected in European Union by Regulation No 2991/1994 [1]. Due to its relatively high price (3200 USD per ton) comparing to other fats and oils (750 USD per ton of palm oil), it is often the object of frauds involving the dilution with water or the partial replacement with cheaper animal fats or plant oils such as palm oil (PO) [2, 3]. Practices of butter adulteration as well as its detection methods have a long history, which can be divided in two periods: before and after the introduction of margarine in Europe in the late 1860s [4]. The first methods of detecting foreign fats in butter were traditional and classical. As early as 1879, Reichert developed a method based on the different volatilities of constituent fatty acids. In 1887 Meissl modified this method, and in 1904 Polenske described the method of determination of volatile acids insoluble in water [5, 6]. All those methods, even today, are internationally accepted as test standard, but its disadvantage is low repeatability [7]. Recently, intensive works have been conducted aiming at the development of effective instrumental methods to detect butter adulterations. One of the first instrumental methods was the analysis of fatty acid composition using gas chromatography (GC). This method was based on the determination of butyric acid (C4) that is exclusively present in milk fat. Due to the large variation in $\mathrm{C} 4$ in the approximate percentage mass 
fraction range 3.1 and $3.8 \%$, it was difficult to provide qualitative and quantitative information for foreign fat to pure milk fat mass fractions of up to $20 \%[8,9]$. In some laboratories, methods based on the determination of tocochromanols or phytosterols by HPLC are also used $[7,10]$. Presently, adulterants in butter are detected by analyzing triacylglycerols (TAGs) by GC according to the Official method, described in the Regulation EC No 273/2008 [11]. Many efforts have been taken to test the applicability of nonchromatographic approaches, such as NIR [12] or DSC methods. Differential scanning calorimetry has been tested for use in the evaluation of fats authenticity; however, at the beginning mainly crystallization curves were recommended for this purpose [13-15]. Lambelet and Ganguli [13] reported that measurements based on crystallization diagrams have the advantage of avoiding problems linked to polymorphism of fats, so that the results are independent of the thermal treatment of the samples prior to analysis. However, it was shown by the study on milk fat [16] that melting curves are characterized by better reproducibility than crystallization curves, only if the sample is initially heated to destroy any previous crystalline structure. There is also little research regarding the comparison of the feasibility of DSC crystallization and melting curves for monitoring the presence of nonmilk fats. Recently Marikkar et al. [17] used heating and cooling curves to detect contamination of sunflower oil. Until that time, many studies have been conducted to investigate the thermal profile of various oil and fat products, although very often only limited thermodynamic parameters were analyzed, i.e., only temperatures or the enthalpies of phase transitions $[14,18]$. The lack of comparative study on DSC cooling and heating curves of butter with various thermodynamic parameters provided an incentive to conduct this study. Therefore, two complementary objectives were undertaken: (1) to test the suitability of the DSC crystallization and melting curves for distinguishing the genuine butterfat (BF) from adulterated by support of chemometric method, i.e., principal component analysis (PCA); (2) to classify and to select by PCA, the DSC parameters such as temperature, enthalpy, peak height and partial surface area, which allow the best differentiation of butterfat samples with various level of palm oil added as adulterant.

\section{Materials and methods}

\section{Materials}

The experimental material comprised dehydrated butterfat (BF) from a local dairy and refined palm oil (PO) (Elstar Oils SA, Poland). Prior to use, palm oil and genuine butterfat were liquefied and mixed to get following percentage mass fraction of PO: $0,2,5,10,15,20,25,30$ and $35 \%$ $(\mathrm{w} / \mathrm{w})$. The resulting mixtures were then vortexed.

\section{Differential scanning calorimetry (DSC)}

A Perkin-Elmer DSC 7 differential scanning calorimeter (Perkin-Elmer, Norwalk) equipped with an Intracooler II and running under Pyris software was used to examine crystallization and melting properties of butterfat. Nitrogen ( $99.999 \%$ purity) was the purge gas. The DSC was calibrated using indium (m.p. $156.6^{\circ} \mathrm{C}, \Delta H_{\mathrm{f}}=28.45 \mathrm{~J} \mathrm{~g}^{-1}$ ) and n-dodecane (m.p. $-9.65^{\circ} \mathrm{C}, \Delta H_{\mathrm{f}}=216.73 \mathrm{~J} \mathrm{~g}^{-1}$ ). Samples of fat $(9-10 \mathrm{mg})$ were weighed into aluminum pans of $20 \mu \mathrm{L}$ (Perkin-Elmer, No. 0219-0062) and hermetically sealed. The reference was an empty, hermetically sealed aluminum pan. The calibration of the calorimeter was controlled using capric acid (m.p. $31.6^{\circ} \mathrm{C}$ ). The sample pan was placed in the calorimeter at $25^{\circ} \mathrm{C}$ and then subjected to the following time-temperature program: (1) heating and isotherm for $5 \mathrm{~min}$ at $60{ }^{\circ} \mathrm{C}$ to melt all the crystals and nuclei; (2) cooling at $5{ }^{\circ} \mathrm{C} \min ^{-1}$ to $-40{ }^{\circ} \mathrm{C}$; (3) isotherm for $3 \mathrm{~min}$ at $-40{ }^{\circ} \mathrm{C}$; and (4) heating at $5{ }^{\circ} \mathrm{C}$ $\min ^{-1}$ to $60{ }^{\circ} \mathrm{C}$. Five replicates were analyzed for each sample. From the crystallization curves, the peak temperature $\left(T_{\mathrm{c}} 1, T_{\mathrm{c}} 2\right)$, enthalpy of crystallization $\Delta H_{\mathrm{c}}\left(\mathrm{J} \mathrm{g}^{-1}\right)$, peak heights $h_{\mathrm{c}} 1, h_{\mathrm{c}} 2\left(\mathrm{~mW} \mathrm{~g}^{-1}\right)$ and area of peaks $\Delta H_{\mathrm{c}} 1$, $\Delta H_{\mathrm{c}} 2(\%)$ were measured. The following parameters were analyzed from the melting curve: $T_{\mathrm{m}} 1$-melting point of the first peak (melting of the low melting fraction, LMF), $\mathrm{T}_{\mathrm{m}}$ 2-temperature of the second melting peak of the medium melting fraction (MMF), $T_{\text {end }}$ - final melting temperature (clarification temperature), and enthalpy $\Delta H_{\mathrm{m}}\left(\mathrm{J} \mathrm{g}^{-1}\right)$ determined as the area limited by the melting curve and the base line. Moreover, the area of LMF $-\Delta H_{\mathrm{m}} 1$ (\%), MMF $-\Delta H_{\mathrm{m}} 2(\%)$ and $\mathrm{HMF}-\Delta H_{\mathrm{m}} 3$ as well as peak heights $h_{\mathrm{m}} 1, h_{\mathrm{m}} 2$ and $h_{\mathrm{m}} 3\left(\mathrm{~mW} \mathrm{~g}^{-1}\right)$ was calculated.

\section{Statistics}

All statistical analyses were conducted using Statistica 10.0 software (StatSoft. Inc., USA). Results were presented in the form of a mean and relative standard deviation RSD. To investigate significant differences at the significance level $p<0.05$ between various concentrations of palm oil in butterfat, one-way analysis of variance (ANOVA) and post hoc Tukey's test to create statistically homogeneous groups were carried out. The principal component analysis (PCA) was also applied. The data matrix consisted of variables and objects was constructed. The DSC parameters of melting and crystallization curves (peak temperatures, enthalpies, peak heights) were considered as variables. The concentrations of palm oil in butterfat $(0,2$, $5,10,15,20,25,30$ and $35 \%$ ) were objects. 


\section{Results}

\section{DSC crystallization and melting results of pure butterfat and its mixtures with palm oil}

Figure 1a, b shows typical crystallization and melting curves of pure butterfat and its mixtures with palm oil at concentration of $2,5,10,15,20,25,30$ and $35 \%(w / w)$. On the crystallization profiles (Fig. 1a), two exothermic peaks $\left(T_{\mathrm{c}} 1, T_{\mathrm{c}} 2\right)$ can be observed. The shape of the curve as well as the position of the crystallization peaks were altered with increasing content of palm oil. The most marked change was the rise of the first peak height $\left(h_{\mathrm{c}} 1\right)$ and the distance between peaks $T_{\mathrm{c}} 1$ and $T_{\mathrm{c}} 2$. In Table 1 , it is shown how the following DSC parameters are affected by the addition of palm oil from 2 to $35 \%$. The temperature of the first peak $\left(T_{\mathrm{c}} 1\right)$, peak area $\left(\Delta H_{\mathrm{c}} 1\right)$ and height $\left(h_{\mathrm{c}} 1\right)$ were increasing, while all the parameters for the second peak $\left(T_{\mathrm{c}} 2, \Delta H_{\mathrm{c}} 2, h_{\mathrm{c}} 2\right)$ were decreasing. Statistically significant $(p<0.05)$ changes were noticed for the peak area and height of both peaks. When analyzing the first peak, area rises from 7.79 to $13.3 \%$ and peak height from 264.6 to $330.1 \mathrm{~mW} \mathrm{~g}^{-1}$. In turn, for the second peak depletion was observed, for peak area from 92.22 to $85.94 \%$ and for peak height from 330.23 to $278.88 \mathrm{~mW} \mathrm{~g}^{-1}$.
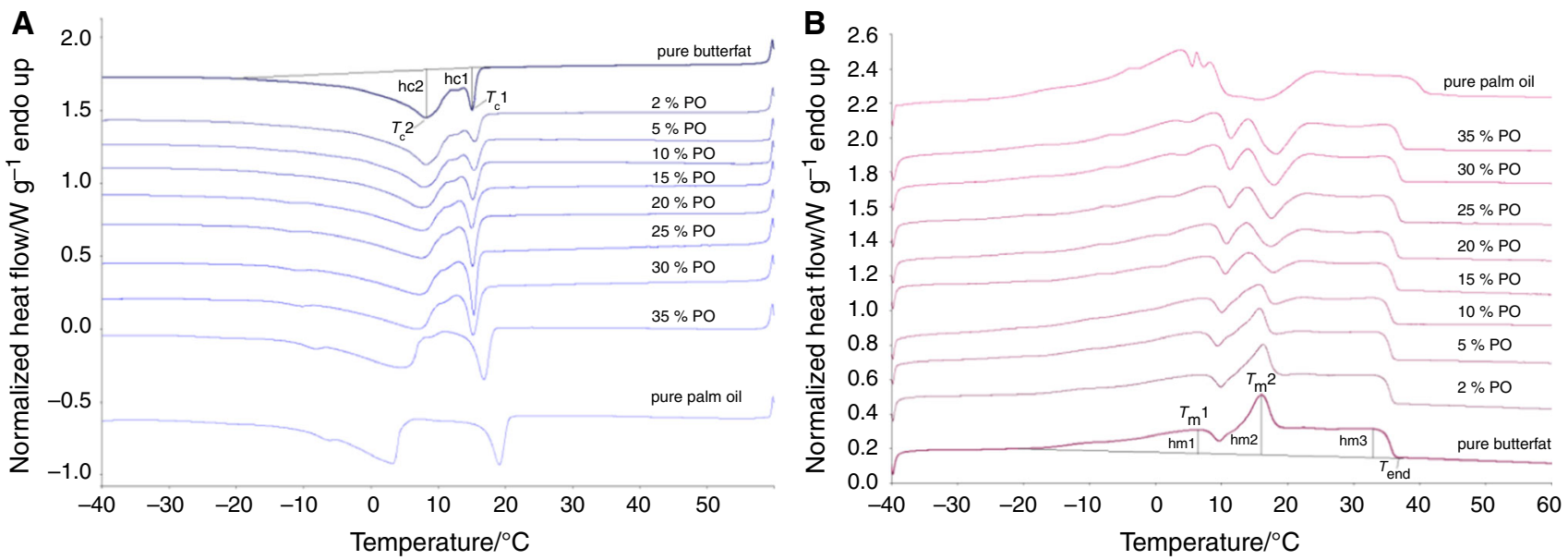

Fig. 1 a DSC crystallization and b DSC melting curves of pure milk fat (BF) and mixtures with palm oil (0, 2, 5, 10, 15, 20, 25, 30 and 35 \%)

Table 1 DSC results of crystallization properties of butterfat and its mixtures with palm oil

\begin{tabular}{|c|c|c|c|c|c|c|c|}
\hline \multirow[t]{3}{*}{ Palm oil content $/ \%$} & \multicolumn{7}{|c|}{ DSC parameters of the crystallization process } \\
\hline & \multicolumn{2}{|c|}{ Temperature $/{ }^{\circ} \mathrm{C}$} & \multirow{2}{*}{$\begin{array}{l}\text { Enthalpy/J g } \\
\Delta H_{\mathrm{c}}\end{array}$} & \multicolumn{2}{|c|}{ Peak area/\% } & \multicolumn{2}{|c|}{ Peak height $/ \mathrm{mW} \mathrm{g}^{-1}$} \\
\hline & $T_{\mathrm{c}} 1$ & $T_{\mathrm{c}} 2$ & & $\Delta H_{\mathrm{c}} 1$ & $\Delta H_{\mathrm{c}} 2$ & $h_{\mathrm{c}} 1$ & $h_{\mathrm{c}} 2$ \\
\hline 0 & $14.88^{\mathrm{a}}$ & $8.15^{\mathrm{ab}}$ & $63.02^{\mathrm{a}}$ & $7.79^{\mathrm{a}}$ & $92.22^{\mathrm{a}}$ & $264.60^{\mathrm{abc}}$ & $330.23^{\mathrm{b}}$ \\
\hline 2 & $15.31^{\mathrm{b}}$ & $8.19^{\mathrm{a}}$ & $62.90^{\mathrm{ab}}$ & $7.44^{\mathrm{a}}$ & $92.56^{\mathrm{a}}$ & $197.26^{\mathrm{c}}$ & $343.08^{\mathrm{a}}$ \\
\hline 5 & $15.01^{\mathrm{ab}}$ & $7.81^{\mathrm{abc}}$ & $61.60^{\mathrm{b}}$ & $8.75^{\mathrm{b}}$ & $91.25^{\mathrm{b}}$ & $188.33^{\mathrm{bc}}$ & $317.37^{\mathrm{c}}$ \\
\hline 10 & $14.87^{\mathrm{a}}$ & $7.81^{\mathrm{abc}}$ & $61.78^{\mathrm{b}}$ & $9.49^{\mathrm{c}}$ & $90.27^{\mathrm{c}}$ & $268.84^{\mathrm{abc}}$ & $290.38^{d}$ \\
\hline 15 & $14.89^{\mathrm{a}}$ & $7.68^{\mathrm{bc}}$ & $63.41^{\mathrm{a}}$ & $10.25^{\mathrm{d}}$ & $89.35^{\mathrm{d}}$ & $306.62^{\mathrm{a}}$ & $283.56^{\mathrm{de}}$ \\
\hline 20 & $14.96^{\mathrm{ab}}$ & $7.48^{\mathrm{cd}}$ & $62.64^{\mathrm{ab}}$ & $11.26^{\mathrm{e}}$ & $88.31^{\mathrm{e}}$ & $330.34^{\mathrm{a}}$ & $278.22^{\mathrm{e}}$ \\
\hline 25 & $15.14^{\mathrm{ab}}$ & $7.49^{\mathrm{cd}}$ & $63.52^{\mathrm{a}}$ & $11.93^{\mathrm{f}}$ & $87.47^{\mathrm{f}}$ & $344.10^{\mathrm{a}}$ & $279.96^{\mathrm{e}}$ \\
\hline 30 & $15.07^{\mathrm{ab}}$ & $7.06^{\mathrm{de}}$ & $62.73^{\mathrm{ab}}$ & $12.66^{\mathrm{g}}$ & $86.70^{\mathrm{g}}$ & $295.52^{\mathrm{ab}}$ & $277.72^{\mathrm{e}}$ \\
\hline 35 & $15.11^{\mathrm{ab}}$ & $6.91^{\mathrm{e}}$ & $63.72^{\mathrm{a}}$ & $13.30^{\mathrm{h}}$ & $85.94^{\mathrm{h}}$ & $330.10^{\mathrm{a}}$ & $278.88^{\mathrm{e}}$ \\
\hline $\mathrm{RSD}_{\max }$ & 1.56 & 2.88 & 1.43 & 2.9 & 0.32 & 22.61 & 2.8 \\
\hline $\mathrm{RSD}_{\min }$ & 0.3 & 0.67 & 0.40 & 0.75 & 0.06 & 3.75 & 0.49 \\
\hline
\end{tabular}

RSD—relative standard deviation calculated in $\%$ for $n=5$

a, b, c, etc.-group averages with different superscripts differ significantly within columns $(p<0.05)$ 
On the melting profile of pure butterfat (Fig. 1b), a big endothermic transition from $-40{ }^{\circ} \mathrm{C}$ to about $36-37{ }^{\circ} \mathrm{C}$ is visible, comprising two peaks $T_{\mathrm{m}} 1$ and $T_{\mathrm{m}} 2$, corresponding to low (LMF) and medium (MMF) melting fractions, and a plateau with a pair of shoulder peaks, recognized as high melting fraction (HMF). The first peak $T_{\mathrm{m}} 1$ is found at a temperature of $6.7{ }^{\circ} \mathrm{C}$, the next $T_{\mathrm{m}} 2$ is the major peak with a temperature near $16.2{ }^{\circ} \mathrm{C}$, and the transition ends at temperature $T_{\text {end }}$ at about $36.3{ }^{\circ} \mathrm{C}$ (Table 2). In Fig. 1b, it is also shown how an addition of palm oil affects the DSC melting curves of butterfat, particularly in terms of the position and shape (width and height) of peaks.

In Table 2, DSC results of melting process are presented. It can be seen that with increasing content of PO, the first peak $T_{\mathrm{m}} 1$ and the end transition point $T_{\text {end }}$ were shifted to higher temperatures, while the second peak moved to lower temperatures from 16.23 to $13.86{ }^{\circ} \mathrm{C}$. An increase in the amount of the adulterant leads also to an increase in the relative area $\left(\Delta H_{\mathrm{m}} 1\right)$ and height $\left(h_{\mathrm{m}} 1\right)$ of the first peak (LMF) and a decrease in the area $\left(\Delta H_{\mathrm{m}} 2\right)$ and height $\left(h_{\mathrm{m}} 2\right)$ of the second peak, which results in a change in proportions of areas and heights of peaks $h_{\mathrm{m}} 1$ and $h_{\mathrm{m}} 2$. The ratio of the area and the height of the first to the second peak increased with an increasing amount of PO in butterfat. All of the above observations provide a basis for the search for existing correlations between palm oil contents in butterfat and the thermodynamic parameters of the crystallization melting curve. In Table 3, results of correlation analysis between DSC parameters and palm oil content in butterfat are presented, which are expressed as

Table 2 DSC results of melting properties of butterfat and its mixtures with palm oil

\begin{tabular}{|c|c|c|c|c|c|c|c|c|c|c|}
\hline \multirow[t]{3}{*}{ Palm oil content $/ \%$} & \multicolumn{10}{|c|}{ DSC parameters of the melting process } \\
\hline & \multicolumn{3}{|c|}{ Temperature $/{ }^{\circ} \mathrm{C}$} & \multirow{2}{*}{$\begin{array}{l}\text { Enthalpy/J g } \\
\Delta H_{\mathrm{m}}\end{array}$} & \multicolumn{3}{|c|}{ Peak area/\% } & \multicolumn{3}{|c|}{ Peak height $/ \mathrm{mW} \mathrm{g}^{-1}$} \\
\hline & $T_{\mathrm{m}} 1$ & $T$ & $T_{\text {end }}$ & & $\Delta H_{\mathrm{m}} 1$ & $\Delta H_{\mathrm{m}} 2$ & $\Delta H_{\mathrm{m}} 3$ & $h_{\mathrm{m}} 1$ & $h_{\mathrm{m}} 2$ & $h_{\mathrm{m}} 3$ \\
\hline 0 & $6.73^{\mathrm{a}}$ & $16.23^{\mathrm{a}}$ & $36.33^{\mathrm{b}}$ & $83.65^{\mathrm{b}}$ & $33.63^{\mathrm{a}}$ & $31.1^{\mathrm{a}}$ & $35.28^{\mathrm{a}}$ & $145.25^{\mathrm{a}}$ & $345.13^{\mathrm{a}}$ & $164.73^{\mathrm{a}}$ \\
\hline 2 & $6.81^{\mathrm{a}}$ & $16.05^{\mathrm{a}}$ & $35.83^{\mathrm{a}}$ & $83.91^{\mathrm{bc}}$ & $35.26^{\mathrm{b}}$ & $28.14^{\mathrm{b}}$ & $36.60^{\mathrm{b}}$ & $149.67^{\mathrm{b}}$ & $321.86^{\mathrm{b}}$ & $164.48^{\mathrm{a}}$ \\
\hline 5 & $6.93^{\mathrm{a}}$ & $15.55^{\mathrm{b}}$ & $36.10^{\mathrm{ab}}$ & $85.96^{\mathrm{d}}$ & $38.27^{\mathrm{c}}$ & $23.87^{\mathrm{c}}$ & $37.87^{\mathrm{c}}$ & $163.20^{\mathrm{c}}$ & $283.13^{\mathrm{c}}$ & $164.17^{\mathrm{a}}$ \\
\hline 10 & $7.05^{\mathrm{a}}$ & $15.21^{\mathrm{b}}$ & $36.21^{\mathrm{ab}}$ & $85.28^{\mathrm{cd}}$ & $40.80^{\mathrm{d}}$ & $20.35^{\mathrm{d}}$ & $38.85^{\mathrm{d}}$ & $176.26^{\mathrm{d}}$ & $234.66^{\mathrm{d}}$ & $162.00^{\mathrm{a}}$ \\
\hline 15 & $7.69^{\mathrm{b}}$ & $13.89^{c}$ & $36.65^{b c}$ & $81.40^{\mathrm{a}}$ & $43.35^{\mathrm{e}}$ & $16.56^{\mathrm{e}}$ & $40.09^{\mathrm{f}}$ & $183.82^{\mathrm{e}}$ & $209.00^{\mathrm{e}}$ & $155.70^{\mathrm{b}}$ \\
\hline 20 & $8.11^{\mathrm{c}}$ & $13.89^{c}$ & $36.99^{\mathrm{cd}}$ & $81.85^{\mathrm{a}}$ & $46.59^{f}$ & $13.94^{\mathrm{f}}$ & $39.47^{\mathrm{e}}$ & $195.66^{\mathrm{f}}$ & $203.82^{\mathrm{ef}}$ & $152.90^{\mathrm{b}}$ \\
\hline 25 & $8.16^{\mathrm{c}}$ & $13.75^{\mathrm{c}}$ & $36.98^{\mathrm{cd}}$ & $81.07^{\mathrm{a}}$ & $49.1^{\mathrm{g}}$ & $12.2^{\mathrm{g}}$ & $38.69^{\mathrm{d}}$ & $204.22^{\mathrm{g}}$ & $201.56^{\mathrm{ef}}$ & $150.80^{\mathrm{bc}}$ \\
\hline 30 & $8.42^{\text {cd }}$ & $13.87^{\mathrm{c}}$ & $37.26^{\mathrm{d}}$ & $81.67^{\mathrm{a}}$ & $52.55^{\mathrm{h}}$ & $10.84^{\mathrm{h}}$ & $36.60^{\mathrm{b}}$ & $216.80^{h}$ & $195.08^{f}$ & $145.26^{\mathrm{c}}$ \\
\hline 35 & $8.57^{\mathrm{d}}$ & $13.86^{\mathrm{c}}$ & $37.40^{\mathrm{d}}$ & $86.34^{\mathrm{d}}$ & $54.59^{\mathrm{i}}$ & $10.40^{\mathrm{h}}$ & $35.01^{\mathrm{a}}$ & $233.53^{\mathrm{i}}$ & $199.58^{\mathrm{ef}}$ & $149.53^{b c}$ \\
\hline $\mathrm{RSD}_{\max }$ & 2.28 & 2.27 & 0.85 & 1.35 & 1.32 & 2.1 & 1.21 & 2.69 & 3.55 & 4.56 \\
\hline $\mathrm{RSD}_{\min }$ & 0.78 & 0.59 & 0.28 & 0.29 & 0.26 & 0.42 & 0.41 & 0.24 & 0.87 & 0.38 \\
\hline
\end{tabular}

RSD—relative standard deviation calculated in \% for $n=5$

a, b, c, etc.- - group averages with different superscripts differ significantly within columns $(p<0.05)$

Table 3 Correlation coefficients $(r)$ calculated between palm oil content in butterfat and DSC crystallization and melting parameters

\begin{tabular}{|c|c|c|c|c|c|c|c|c|c|}
\hline \multicolumn{3}{|c|}{ Temperature $/{ }^{\circ} \mathrm{C}$} & \multirow{2}{*}{$\begin{array}{l}\text { Enthalpy } / \mathrm{J} \mathrm{g}^{-1} \\
\Delta H_{\mathrm{c}}\end{array}$} & \multicolumn{3}{|c|}{ Peak area/\% } & \multicolumn{3}{|c|}{ Peak height $/ \mathrm{mW} \mathrm{g}^{-1}$} \\
\hline$T_{\mathrm{c}} 1$ & $T_{\mathrm{c}} 2$ & & & & & $\Delta H_{\mathrm{c}} 2$ & $h_{\mathrm{c}}$ & & $h_{\mathrm{c}} 2$ \\
\hline \multicolumn{10}{|c|}{ Correlation coefficients $(r)$ for DSC crystallization parameters } \\
\hline 0.075 & $-0.871^{*}$ & & 0.361 & \multicolumn{2}{|c|}{$0.989 *$} & $-0.990 *$ & \multicolumn{2}{|c|}{$0.605^{*}$} & $-0.837 *$ \\
\hline \multicolumn{3}{|c|}{ Temperature $/{ }^{\circ} \mathrm{C}$} & Enthalpy/J $\mathrm{g}^{-1}$ & \multicolumn{3}{|c|}{ Peak area/\% } & \multicolumn{3}{|c|}{ Peak height $/ \mathrm{mW} \mathrm{g}^{-1}$} \\
\hline$T_{\mathrm{m}} 1$ & $T_{\mathrm{m}} 2$ & $T_{\text {end }}$ & $\Delta H_{\mathrm{m}}$ & $\Delta H_{\mathrm{m}} 1$ & $\Delta H_{\mathrm{m}} 2$ & $\Delta H_{\mathrm{m}} 3$ & $h_{\mathrm{m}} 1$ & $h_{\mathrm{m}} 2$ & $h_{\mathrm{m}} 3$ \\
\hline \multicolumn{10}{|c|}{ Correlation coefficients $(r)$ for DSC melting parameters } \\
\hline $0.958^{*}$ & $-0.878 *$ & $0.882 *$ & -0.229 & $0.997 *$ & $-0.958^{*}$ & -0.026 & $0.993 *$ & $-0.870 *$ & $-0.900 *$ \\
\hline
\end{tabular}

* Correlation significant at $p<0.05$ 


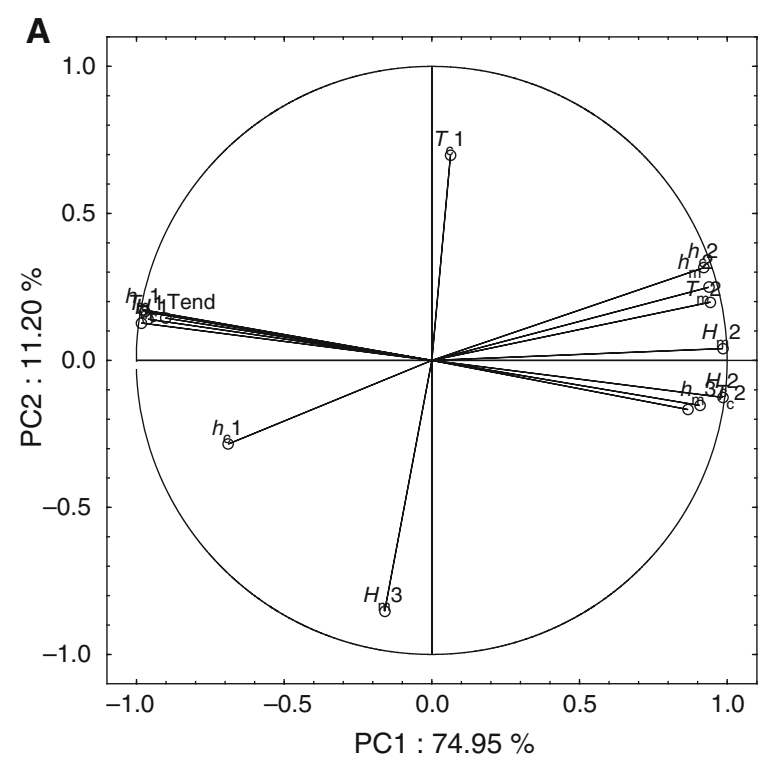

Fig. 2 a The loading and score plots $\mathbf{b}$ for PC1 and PC2 analyses of DSC crystallization and melting results. The variables of $T_{\mathrm{c}} 1, T_{\mathrm{c}} 2$, $\Delta H_{\mathrm{c}} 1, \Delta H_{\mathrm{c}} 2, h_{\mathrm{c}} 1, h_{\mathrm{c}} 2, T_{\mathrm{m}} 1, T_{\mathrm{m}} 2, T_{\text {end }}, \Delta H_{\mathrm{m}} 1, \Delta H_{\mathrm{m}} 2, \Delta H_{\mathrm{m}} 3, h_{\mathrm{m}} 1, h_{\mathrm{m}} 2$

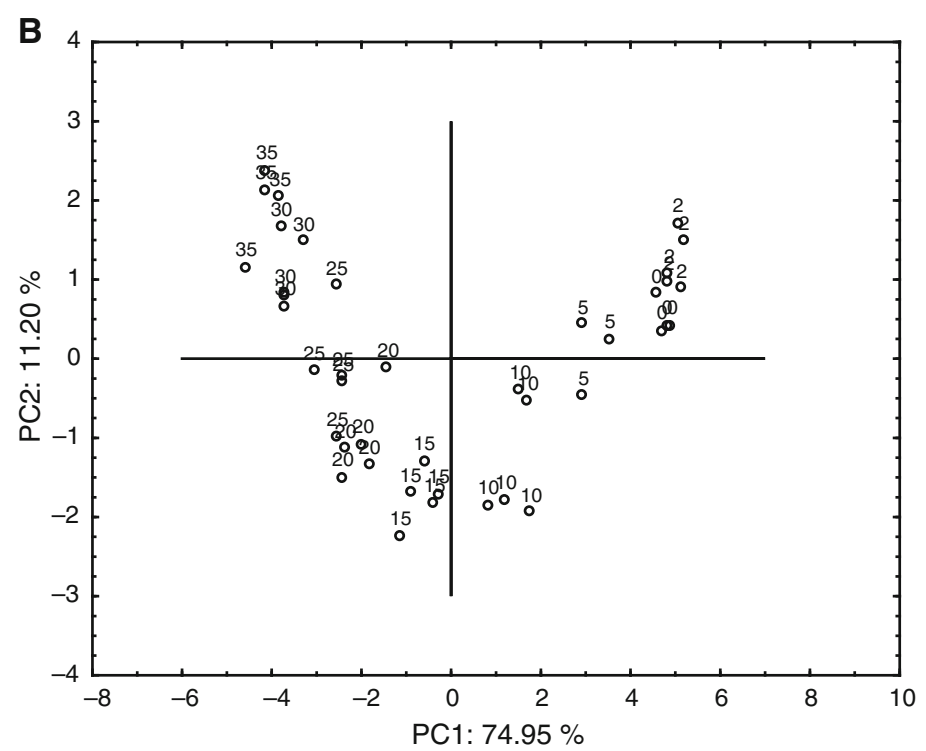

and $h_{\mathrm{m}} 3$ represent various thermodynamic parameters of crystallization and the melting process
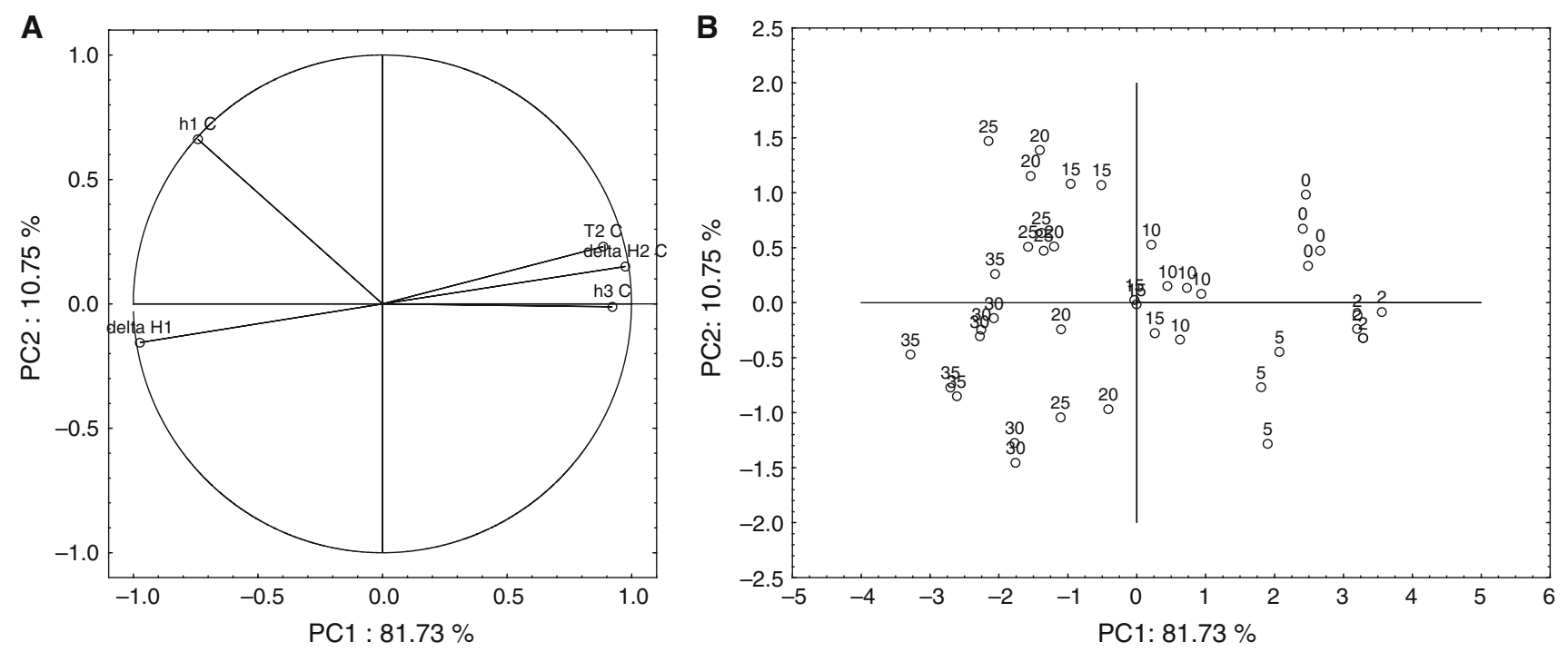

Fig. 3 a The loading and $\mathbf{b}$ score plots for PC1 and PC2 analyses of DSC crystallization results. The variables of $T_{\mathrm{c}} 2, \Delta H_{\mathrm{c}} 1, \Delta H_{\mathrm{c}} 2, h_{\mathrm{c}} 1$ and $h_{\mathrm{c}} 2$, represent various thermodynamic parameters of the crystallization process

Pearson's correlation coefficients $(r)$. The highest coefficients were observed for parameters of peak areas $\left(\Delta H_{\mathrm{c}} 1\right.$, $\left.\Delta H_{\mathrm{c}} 2, \Delta H_{\mathrm{m}} 1, \Delta H_{\mathrm{m}} 2, \Delta H_{\mathrm{m}} 3\right)$ and heights $\left(h_{\mathrm{c}} 1, h_{\mathrm{c}} 2, h_{\mathrm{m}} 1\right.$, $\left.h_{\mathrm{m}} 2, h_{\mathrm{m}} 3\right)$ for crystallization as well as for melting process.

\section{Principal component analysis of a dataset of DSC crystallization and melting results}

Principal component analysis as a statistical tool allows the reduction in a large dataset into more manageable "factors" or "components," which are orthogonal. It is also a method to detect structure in the relationships between variables and to classify the objects. Because in this study a large dataset with many DSC variables was obtained, the next step was to find final a multivariate model, which allows the distinguishing of adulterated samples from genuine butter. Principal component analysis was applied for differentiation and classification samples with various levels of adulterant. Finding this final model was depended on preselection and processing of the input 

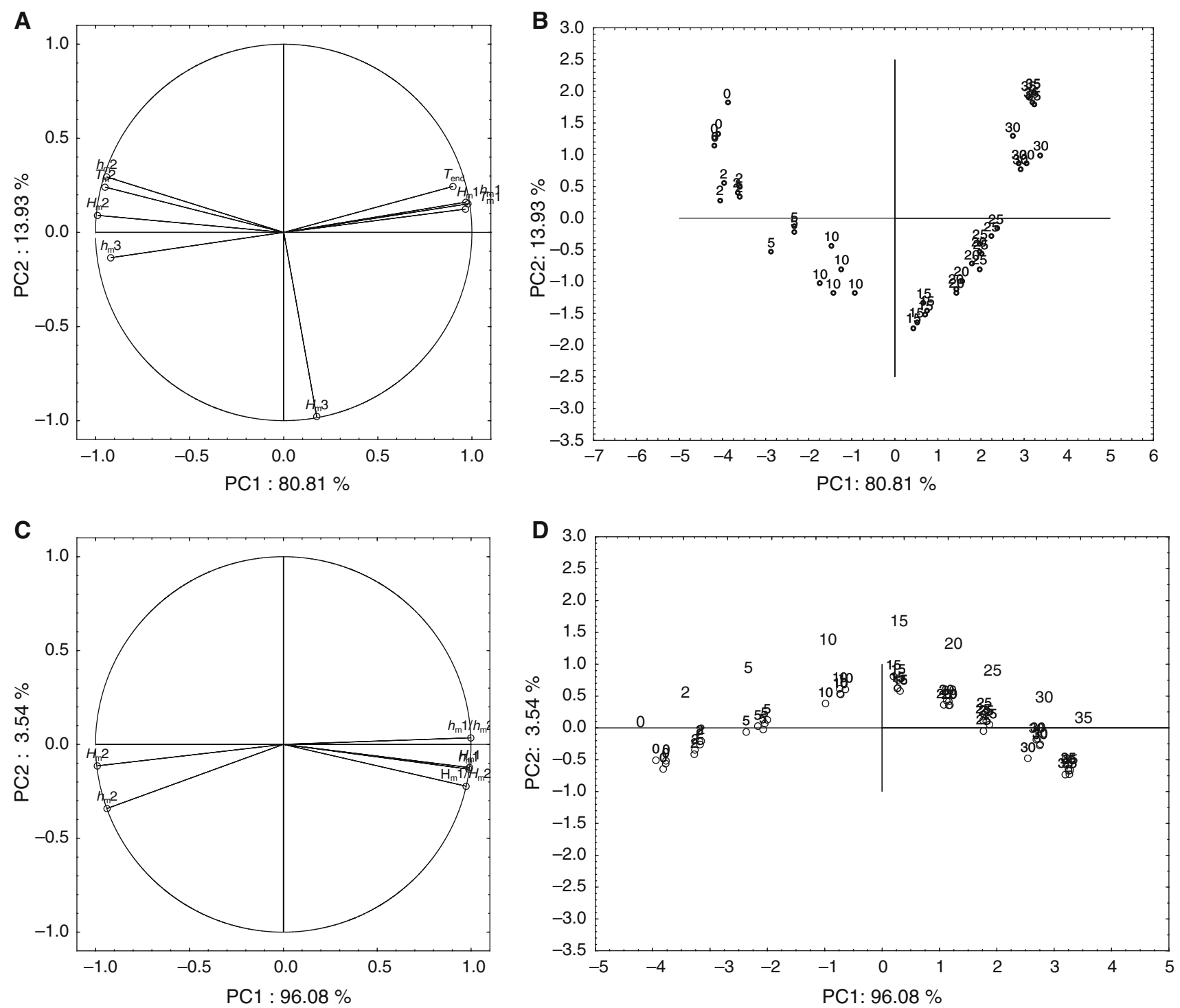

Fig. 4 a The loading and $\mathbf{b}$ score plots for PC1 and PC2 analyses of DSC melting results of $T_{\mathrm{m}} 1, T_{\mathrm{m}} 2, T_{\text {end }}, \Delta H_{\mathrm{m}} 1, \Delta H_{\mathrm{m}} 2, \Delta H_{\mathrm{m}} 3, h_{\mathrm{m}} 1, h_{\mathrm{m}} 2$ and $h_{\mathrm{m}} 3$. $\mathbf{c}$ The loading and $\mathbf{d}$ score plot for the variables of $\Delta H_{\mathrm{m}} 1, \Delta H_{\mathrm{m}} 2, h_{\mathrm{m}} 1, h_{\mathrm{m}} 2, \Delta H_{\mathrm{m}} 1 / \Delta H_{\mathrm{m}} 2$ and $h_{\mathrm{m}} 1 / h_{\mathrm{m}} 2$

data; hence, in the beginning the large dataset of DSC crystallization and melting results was analyzed by PCA. The multivariate data matrix was composed of 9 various concentrations of palm oil and 15 DSC crystallization and melting parameters. One of the PCA results is the eigenvalue plot, which showed that around $95 \%$ of the variation in the data can be explained by four principal components; however, for further analysis, the first two principal components were taken, for which eigenvalues were $>1$, so the amount of variables was reduced from 15 to 2 main principal components (PC). In Fig. 2, plots of loadings (Fig. 2a) and scores (Fig. 2b) with PC1 and PC2 on the $X$ and $Y$ axes are presented. The plot of loadings visualizes relations between variables and the plot of scores, distri- bution of objects (samples). The obtained results showed that the first two PCs describe $86.15 \%$ of the initial variability, where first PC1 explains the observed variability in $74.95 \%$ and PC2 in $11.20 \%$. From the set of variables (Fig. 2a), only crystallization peak temperature $T_{\mathrm{c}} 1$ and HMF peak area $\Delta H_{\mathrm{m}} 3$ are related to $\mathrm{PC} 2$, while the rest of the parameters are highly correlated with $\mathrm{PC} 1$. The score plot (Fig. 2a) shows that PC analysis of the whole dataset cannot give definite information about the differentiation of samples. The separation is not satisfactory, and only samples with concentration 0,2 and $5 \%$ are separated from the rest of the objects. To improve the differentiation, the next step was to apply the PCA method separately for crystallization and melting results. 


\section{Principal component analysis of DSC crystallization results}

In Fig. 3a, b, plots of loadings and scores from PCA of DSC crystallization results are shown. It can be seen that PC1 explains the observed variability in $81.7 \%$ and the second principal component in $10.75 \%$, which gives a total of $92.45 \%$. From Fig. 3b, it is visible that distinction of samples with successive concentrations of palm oil is still insufficient, because only samples with concentrations of 0,2 and $5 \%$ of palm oil are well separated. The samples were displayed only in two clusters. The first cluster, composed of very well separated objects (pure butterfat and samples with 2 and $5 \%$ of palm oil), is located on the positive side of the $\mathrm{X}$-axis. The second cluster is located on the negative side of the $\mathrm{X}$-axis and contains the rest of the samples, which are so mixed together that they cannot be separated from each other.

\section{Principal component analysis of DSC melting results}

In Fig. 4a, b, the loading and score plots of PC analysis of DSC melting parameters are presented. Plots of loadings and scores were generated using two principal components (PC1 and PC2), which described $94 \%$ of variation. Only the first two eigenvalues were $>1$. Compared to the crystallization results, in the case of the melting process the separation of samples with consecutive concentration has been improved. The objects on the score plot (Fig. 4b) were divided into four clusters. The first cluster with 0 and $2 \%$ samples and the second with 5 and $10 \%$ samples are located on the negative side of the $X$-axis; the third with 15 , 20 and $25 \%$ samples and the fourth with 30 and $35 \%$ samples are placed on the opposite side. For improving this distinction, the variables of temperatures $T_{\mathrm{m}} 1, T_{\mathrm{m}} 2, T_{\text {end }}$, and parameters of HMF fraction $\left(\Delta H_{\mathrm{m}} 3, h_{\mathrm{m}} 3\right)$ were excluded and new variables $\Delta H_{\mathrm{m}} 1 / \Delta H_{\mathrm{m}} 2, h_{\mathrm{m}} 1 / h_{\mathrm{m}} 2$ were created and analyzed by PCA. The results of analysis with new matrix of variables are presented in Fig. 4c, d. It can be seen in Fig. 4d that objects are displayed in nine clusters and the separation of each concentration is very distinct and far better than in Fig. 4b. At this point, it is important to pay attention to the fact that PCA results for melting parameters are very different from crystallization results. Similar observations were made by Dahimi et al. [19].

\section{Conclusions}

This study has shown that the addition of palm oil as an adulterant to butterfat affects DSC parameters such as temperature, enthalpy and peak height of crystallization and melting process. Principal component analysis was applied to parameters of crystallization and melting curves. The presented results proved that the combination of DSC technique with PCA allows the differentiation of samples with various levels of palm oil. Comparing PCA results of crystallization and/or melting parameters, it can be concluded that the best separation of samples with different levels of palm oil was possible by using only parameters of the melting process. Successive concentrations of palm oil in butterfat were distinctly separated from each other, whereas in the model with only crystallization or crystallization and melting results, samples were mixed together and were not distinguishable. In summary, the DSC technique is suitable for the quantitative assessment of butter authenticity as well as being able to be used as a simple and fast technique to screen samples prior to TAG analysis, which is an expensive and time-consuming method.

Acknowledgements This research was supported by the National Science Centre, by Grant No. NN 312260538.

Open Access This article is distributed under the terms of the Creative Commons Attribution 4.0 International License (http://crea tivecommons.org/licenses/by/4.0/), which permits unrestricted use, distribution, and reproduction in any medium, provided you give appropriate credit to the original author(s) and the source, provide a link to the Creative Commons license, and indicate if changes were made.

\section{References}

1. Council Regulation (EC) No 2991/94 of 5 December 1994 laying down standards for spreadable fats.

2. http://www.simedarby.com/upload/Palm_Oil_Facts_and_Figures.pdf.

3. http://www.fao.org/docrep/012/al179e/al179e.pdf.

4. Deelstra H, Thorburn D, Burns M, Walker J. The adulteration of food, lessons from the past, with reference to butter, margarine and fraud. Eur Food Res Technol. 2014;239:725-44. doi:10. 1007/s00217-014-2274-0.

5. AOCS. Official methods and recommended practices of the American oil chemists' society. Reichert-Meissl Value. Cd 5-40 (09).

6. AOAC. The Association of Official Agricultural Chemists-Official method 925.41. Acids (volatile) in oils and fats. 17th edn; 2000.

7. Nogala-Kałucka M, Pikul J, Siger A. Applying liquid chromatography (HPLC) to study the genuineness of butter. ZywnNauk Technol Ja. 2008;58:47-56.

8. Molkentin J, Precht D. Representative determination of the butyric acid content in European milk fats. Milchwissenschaft. 1987;52:82-5.

9. Glaeser H. Determination of the milk fat content of fat mixtures. Grasas Aceites. 2002;53:357-8.

10. Derewiaka D, Sosińska E, Obiedziński M, Krogulec A, Czaplicki S. Determination of the adulteration of butter. Eur J Lipid Sci Technol. 2011;113:1005-11.

11. Commission Regulation (EC) No 273/2008 of 5 March 2008 laying down detailed rules for the application of Council Regulation (EC) No 1255/1999 as regards methods for the analysis and quality evaluation of milk and milk products. 
12. Heussen PCM, Janssen H-G, Samwel IBM, van Duynhoven JPM. The use of multivariate modelling of near infra-red spectra to predict the butter fat content of spreads. Anal Chim Acta. 2007;595:176-81.

13. Lambelet P, Ganguli NC. Detection of pig and buffalo body fat in cow and buffalo ghees by differential scanning calorimetry. J Am Oil Chem Soc. 1983;60:1005-8.

14. Coni E, Di Pasquale M, Coppolelli P, Bocca A. Detection of animal fats in butter by differential scanning calorimetry: a pilot study. J Am Oil Chem Soc. 1994;71:807-10.

15. Aktas N, Kaya M. Detection of beef body fat and margarine in butterfat by differential scanning calorimetry. J Therm Anal Calorim. 2001;66:795-801.
16. Tomaszewska-Gras J. Melting and crystallization DSC profiles of milk fat depending on selected factors. J Therm Anal Calorim. 2013;113:199-208. doi:10.1007/s10973-013-3087-2.

17. Marikkar JMN, Dzulkifly MH, Nadiha MZN, Man YBC. Detection of animal fat contaminations in sunflower oil by differential scanning calorimetry. Int J Food Prop. 2012;15:683-90.

18. Marikkar JMN, Ghazali HM, Man YBC, Lai OM. Differential scanning calorimetric analysis for determination of some animal fats as adulterants in palm olein. J Food Lipids. 2003;10:63-79.

19. Dahimi O, Rahim AA, Abdulkarim S, Hassan MS, Hashari SBZ, Mashitoh AS, Saadi S. Multivariate statistical analysis treatment of DSC thermal properties for animal fat adulteration. Food Chem. 2014;158:132-8. 